\title{
ANATOMIA DA MADEIRA DE ACACIA DEALBATA LINK ${ }^{1}$
}

\author{
JOSÉ NEWTON CARDOSO MARCHIORI ${ }^{2}$
}

\section{RESUMO}

São anatomicamente descritos os caracteres gerais, macroscópicos e microscópicos da madeira de Acacia dealbata Link. É reconhecido o valor diagnóstico de fibras libriformes não septadas e raios estreitos (1-5 células de largura) para o subgênero Heterophyllum Vassal, ao qual se insere a espécie em estudo.

Palavras-chave: anatomia da madeira, Acacia dealbata, Leguminosae Mimosoideae, Fabaceae, subgênero Heterophyllum Vassal, série Botryocephalae Bentham.

\section{SUMMARY}

[Wood anatomy of Acacia dealbata Link].

The general, macroscopic and microscopic wood features of Acacia dealbata Link are described.

Non-septated fibres and thin rays (1-5 cells wide) are recognized as typical to Heterophyllum Vassal, the subgenus that embraces the studied species.

Key words: wood anatomy, Acacia dealbata, Leguminosae Mimosoideae, Fabaceae, subgenus Heterophyllum Vassal, series Botryocephalae Bentham.

\section{INTRODUÇÃO}

A literatura anatômica sobre o gênero Acacia (Tourn.) Mill. não corresponde, por escassa, à importância econômica e diversidade de espécies nativas e cultivadas no continente americano. Record \& Hess (1949), por exemplo, não fazem qualquer referência ao mesmo em seu clássico Timbers of the New World, a despeito do numeroso contingente de espécies nativas nas três Américas.

Em estudo de madeiras argentinas, Cozzo (1951) não observou diferenças anatômicas importantes nas 13 espécies investigadas, motivo pelo qual ele se refere ao gênero como estruturalmente homogêneo. $\mathrm{O}$ autor fornece uma diagnose anatômica para o conjunto das espécies e uma chave dicotômica para a identificação das mesmas.

Em contraste com o autor argentino, Marchiori (1980) encontrou uma relativa seme-

1 Recebido em 15-2-2011 e aceito para publicação em 27-5-2011.

2 Engenheiro Florestal, Dr. Bolsista de Produtividade em Pesquisa (CNPq - Brasil). Professor Titular do Departamento de Ciências Florestais, Universidade Federal de Santa Maria. Santa Maria, RS, Brasil. marchiori@pq.cnpq.br lhança estrutural entre Acacia bonariensis Gill. ex Hook. et Arn. e Acacia tucumanensis Gris., pertencentes à série Vulgares Benth., e diferenças importantes entre estas e Acacia caven (Mol.) Mol., da série Gummiferae Benth. Para a distinção dos referidos grupos infragenéricos, o autor valeu-se da presença ou não de septos em fibras, do arranjo do parênquima axial e da morfologia dos raios.

Em estudo de 37 espécies sul-africanas, Robbertse et al. (1980) encontraram pouca variação anatômica na madeira, valendo-se, para a separação dos subgêneros, da dimensão dos raios e, com menor importância, da presença de anéis de crescimento, do número de poros $/ \mathrm{mm}^{2}$ e da distribuição do parênquima axial. Pelo primeiro destes caracteres, todas as 14 espécies estudadas do subgênero Aculeiferum Vassal tinham raios estreitos (2-5-seriados), em contraste com as 23 espécies investigadas do subgênero Acacia, distinguidas por terem raios mais largos (4-14 células).

Originária do leste da Austrália, em Nova Gales do Sul, Queensland e Victoria (Ewart, 1930), Acacia dealbata Link recebe os nomes comuns de acácia, aromo, mimosa e acácia-francesa (Burkart, 1978). Árvore ornamental, pela folhagem verde-glauca e vistosa floração ama- 
relo-dourada, a espécie também produz boa lenha e casca com tanino (Mattos, 1980). Sob o ponto de vista taxonômico, a espécie pertence à série Botryocephalae Benth. e ao subgênero Heterophyllum Vassal.

\section{MATERIAL E MÉTODOS}

O material estudado consiste de duas amostras de madeira, obtidas junto ao Instituto de Pesquisas Tecnológicas do Estado de São Paulo (IPT) e à Universidade Federal do Paraná (UFPR), onde constam no acervo das respectivas xilotecas com os seguintes registros:

- IPT 12.297. Procedência: Portugal.

- HDCF 194. Marchiori, J.N.C., s.n., 28-71979; Escola de Florestas, UFPR, Curitiba, Paraná; flores.

De cada amostra foram preparados três corpos-de-prova, orientados para a obtenção de cortes anatômicos nos planos transversal, longitudinal radial e longitudinal tangencial. A microtomia seguiu a técnica padrão no Laboratório de Anatomia da Madeira da Universidade Federal do Paraná: os corpos-de-prova foram amolecidos por fervura em água e seccionados em micrótomo de deslizamento, regulado para a obtenção de cortes anatômicos com espessura nominal de $18 \mu \mathrm{m}$. Os cortes sofreram coloração com acridina-vermelha, crisoidina e azulde-astra (Dujardin, 1964), desidratação em série alcoólica $(25 \%, 50 \%, 75 \%, 90 \%, 95 \%$, duas vezes álcool absoluto), e passaram por xilol, antes de sua montagem em lâminas permanentes, com "Entellan". No caso do macerado, usouse a técnica de Jeffrey (Freund, 1970), coloração com safranina e o mesmo meio de montagem anteriormente referido.

A terminologia, número de medições e descrição da estrutura anatômica seguiu as recomendações da Copant (1973), com as modificações introduzidas por Burger (1979). As determinações estereológicas da percentagem de vasos, parênquima axial, raios e fibras, bem como da percentagem das classes de raios quanto à largura em número de células, seguiram a metodologia utilizada por Marchiori (1980). A cor da madeira foi determinada por comparação com a "Tabela de Cores para Solos" (Munsell, 1971), sob iluminação natural. As fotomicrografias foram tomadas em aparelho Carl Zeiss.

\section{DESCRIÇÃO DA MADEIRA}

Caracteres gerais:

Madeira de cerne e alburno distintos, com alburno estreito, amarelo-palha (HUE 2.5 YR 8/4) e cerne castanho-amarelado (HUE 10YR 7/6). Madeira brilhante, de espelhado contrastado, grã direita, não aromática, macia e de textura média. Figura pouco atrativa, resultante de linhas vasculares e anéis de crescimento.

Caracteres macroscópicos:

Parênquima axial: visível apenas com lente de bolso (10x), escasso, em disposição paratraqueal vasicêntrica.

Raios: visíveis a olho nu em plano transversal, finos, muito freqüentes; também visíveis a olho nu em plano longitudinal tangencial, baixos, não estratificados. Espelhado contrastado, em plano radial.

Poros: visíveis a olho nu, de diâmetro médio, pouco numerosos e em distribuição difusa. Poros solitários e em múltiplos radiais de 2 a 4; sem conteúdos. Linhas vasculares retilíneas, sem conteúdos.

Camadas de crescimento: distintas, individualizadas por zonas fibrosas tangenciais mais escuras.

Outros caracteres: canais secretores axiais, máculas medulares, líber incluso, canais secretores horizontais e estratificação, ausentes.

Caracteres microscópicos:

Vasos: pouco numerosos $\left(5-8-15 / \mathrm{mm}^{2}\right.$; s $=2,35$ ), ocupando $12,2 \%$ da seção transversal da madeira. Poros de diâmetro pequeno a médio $(75-126-178 \mu \mathrm{m} ; \mathrm{s}=20,96)$, de seção oval e parede fina $(1,8-2,8-5 \mu \mathrm{m} ; \mathrm{s}=0,73)$, em distribuição difusa, uniforme (Figura 1A). 

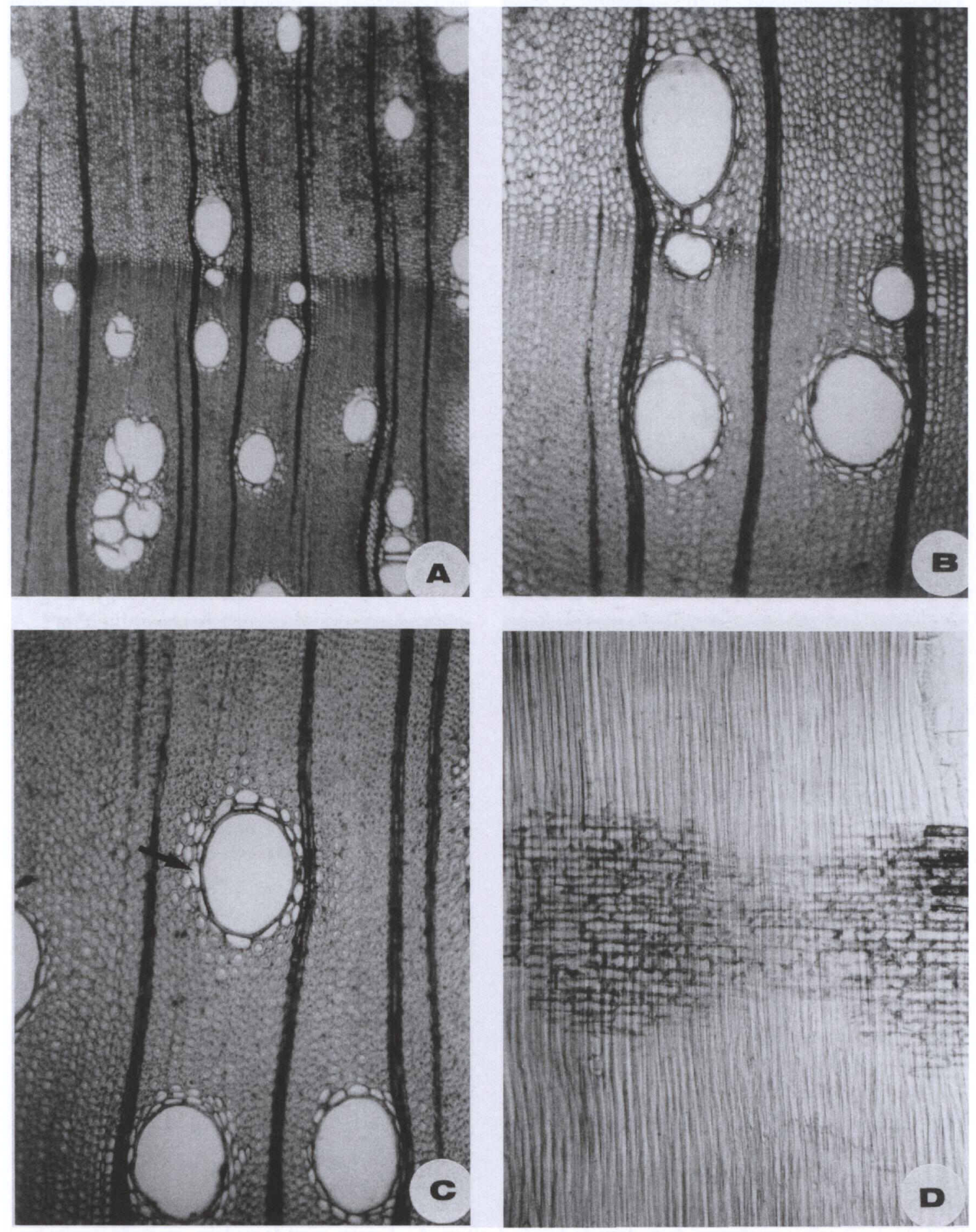

FIGURA 1 - Aspectos anatômicos da madeira de Acacia dealbata. A - Limite de anel de crescimento, porosidade difusa e distribuição dos vasos, em seção transversal. B - Detalhe do limite de anel, com fibras radialmente estreitas e de paredes mais espessas no lenho tardio. C - Parênquima axial vasicêntrico (seta), em detalhe (seção transversal). D - Raio homogêneo, composto inteiramente de células procumbentes (seção longitudinal radial). 

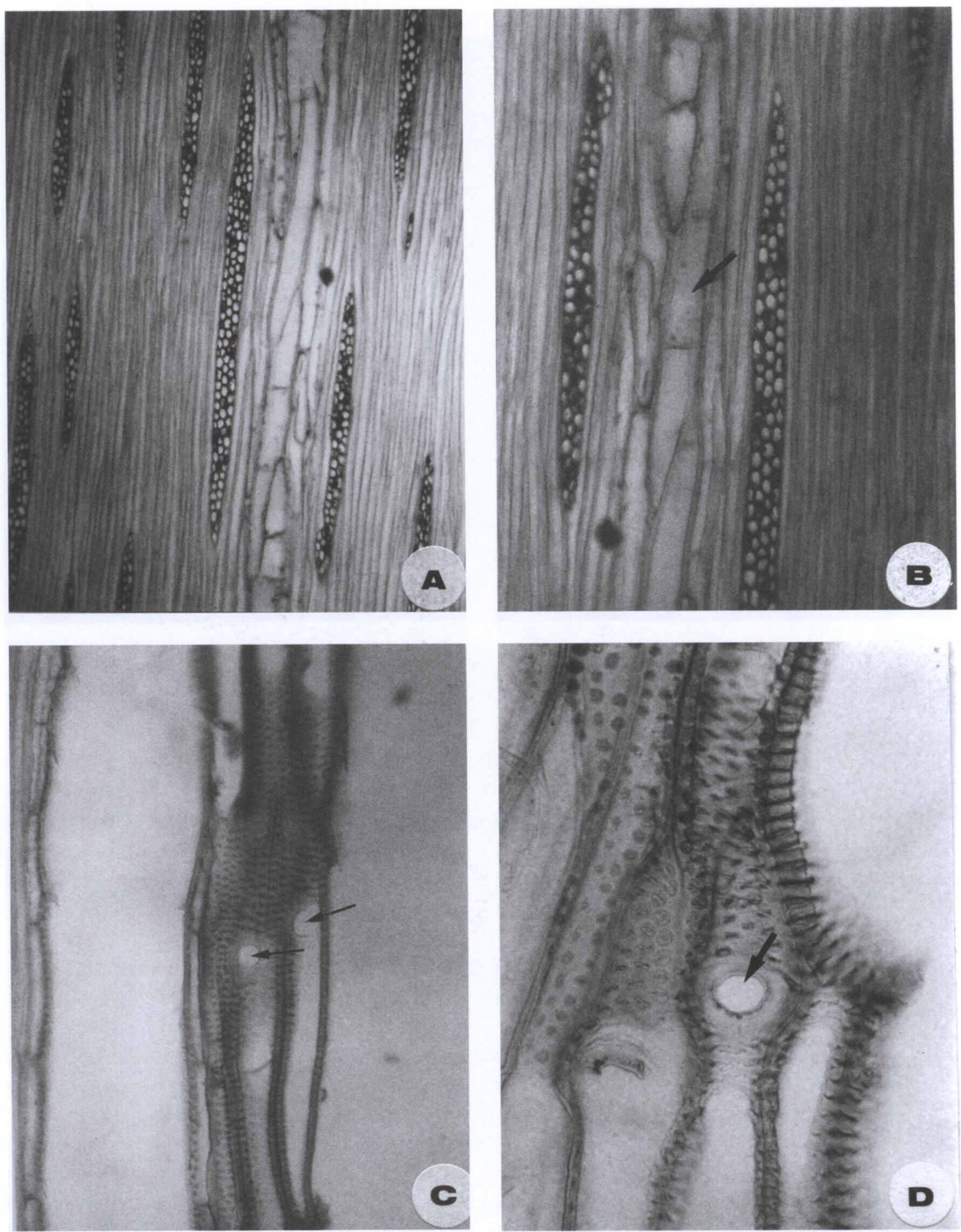

FIGURA 2 - Detalhes anatômicos da madeira de Acacia dealbata. A - Aspecto geral da madeira, em seção longitudinal tangencial. B - Séries de parênquima axial (seta) e raios multisseriados (seção longitudinal tangencial). C - Placas de perfuração simples (setas), em elementos vasculares estreitos (seção longitudinal radial). D - Detalhe de placa de perfuração simples (seta) e pontoado intervascular alterno (seção longitudinal radial). 
Poros solitários, em sua maioria, menos comumente em múltiplos de 2 a 6 , compondo agrupamentos radiais e cachos (Figura 1A). Elementos vasculares curtos $(220-368-470 \mu \mathrm{m}$; $\mathrm{s}=57,66)$, com placas de perfuração simples (Figura 2C, D), em posição oblíqua até transversal ao vaso. Apêndices frequentemente ausentes; quando presentes, curtos (17 - 52-113 $\mu \mathrm{m} ; \mathrm{s}=26,34)$ e dispostos geralmente em uma extremidade. Espessamentos espiralados, ausentes. Pontoações intervasculares alternas, ornamentadas, de diâmetro médio (7 - 8,7 - $12 \mu \mathrm{m}$; $\mathrm{s}=1,29$ ) e forma oval (Figura 2D); abertura lenticular, horizontal, geralmente inclusa. Pontoações raio-vasculares pequenas e arredondadas $(4,5-6,4-9 \mu \mathrm{m}$; $\mathrm{s}=1,31)$. Pontoações parênquimo-vasculares de diâmetro pequeno (5 $-6-8 \mu \mathrm{m}$; $\mathrm{s}=0,93$ ) e forma semelhante às raio-vasculares. Inclusões orgânicas escassas, mesmo no cerne, de cor escura e com aspecto de goma; tilos, ausentes.

Parênquima axial: pouco abundante, ocupando cerca de $10 \%$ do volume da madeira, em arranjo paratraqueal vasicêntrico (Figura 1C), com células parenquimáticas em estreita bainha ao redor dos vasos. Células fusiformes de 167 $264-365 \mu \mathrm{m}$ de altura $(\mathrm{s}=45,63)$ e $12-17-$ $23 \mu \mathrm{m}$ de diâmetro $(s=3,62)$. Séries parenquimáticas axiais de $342-416-538 \mu \mathrm{m}$ de altura $(\mathrm{s}=45,82)$ e $10-26-45 \mu \mathrm{m}$ de diâmetro $(s=10,07)$, compostas por $2-3-4$ células (Figura 2B). Cristais romboédricos de oxalato de cálcio com cerca de $30 \mu \mathrm{m}$, escassos e confinados à periferia do parênquima axial.

Raios: homogêneos, compostos inteiramente de células procumbentes (Figura 1D), ocupando $11,5 \%$ do volume da madeira. Raios pouco numerosos $(3-5,5-8 / \mathrm{mm}$; s $=1,01)$ e de relacionamento normal; raios agregados e fusionados, ausentes. Raios unisseriados muito escassos $(1,7 \%)$, muito baixos $(12-60-115$ $\mu \mathrm{m} ; \mathrm{s}=26,74)$, extremamente finos $(5-7,4-$ $10 \mu \mathrm{m} ; \mathrm{s}=1,35)$, com $1-5-9$ células de altura ( $\mathrm{s}=2,16$ ). Os multisseriados (Figura 2A, B), com 4 células de largura em sua maioria $(48,5 \%)$, menos comumente trisseriados
(36,3\%), bisseriados $(7,6 \%)$, ou com mais de 4 células de largura $(5,9 \%)$; variam de baixos a medianos $(160-460-763 \mu \mathrm{m} ; \mathrm{s}=29,21)$, com $6-31$ - 52 células de altura $(s=10,89)$, e de muito finos a finos $(11-26-36 \mu \mathrm{m} ; \mathrm{s}=5,35)$. Células cristalíferas, envolventes, eretas, esclerosadas, latericuliformes, quadradas e oleíferas, ausentes.

Fibras: libriformes, não septadas, ocupando $66,1 \%$ do volume da madeira; com pontoações simples diminutas, mais abundantes na face radial da parede. Fibras curtas (860 - 1127 - 1420 $\mu \mathrm{m} ; \mathrm{s}=140,97)$, estreitas $(9-12-21 \mu \mathrm{m} ; \mathrm{s}=$ $2,30)$ e de paredes delgadas $(1,2-2,5-3,8 \mu \mathrm{m}$; $\mathrm{s}=0,64)$. Fibras gelatinosas, abundantes. $\mathrm{Na}$ periferia do parênquima axial, as fibras, de paredes mais finas, assemelham-se a células de parênquima em corte transversal.

Outros caracteres: canais secretores, tubos laticíferos e taniníferos, líber incluso, máculas medulares e estratificação, ausentes. Anéis de crescimento distintos, marcados por camada de fibras radialmente estreitas e de paredes mais espessas, no lenho tardio.

\section{ANÁLISE DA ESTRUTURA ANATÔMICA}

A estrutura anatômica da madeira de Acacia dealbata Link distingue-se, facilmente, do observado em Acacia caven (Marchiori, 1980, 1992), Acacia bonariensis (Marchiori, 1980, 1996), e Acacia tucumanensis (Marchiori, 1980, 1994). Destas duas últimas, integrantes da série Vulgares Benth. (ou subgênero Aculeiferum Vassal), o material em estudo separa-se, principalmente, por ter fibras não septadas. Comparada a Acacia caven, integrante da série Gummiferae Benth (ou subgênero Acacia Vassal), Acacia dealbata difere, sobretudo, pelos raios finos (até 5 células de largura), bem como pelas fibras de paredes relativamente estreitas, pouco contrastadas em relação ao parênquima axial, em plano transversal.

Os caracteres anatômicos acima referidos para duas espécies nativas do subgênero Aculeiferum Vassal (ou série Vulgares Benth.) receberam confirmação, em estudos posterio- 
res realizados com outras espécies do mesmo grupo: Acacia recurva Benth. (Marchiori, 1982), Acacia nitidifolia Speg. (Marchiori, 1991a), Acacia plumosa Lowe (Marchiori, 1991b) e Acacia velutina DC. (Marchiori, 1995). Resta frisar que todas estas espécies pertencem, atualmente, ao gênero Senegalia Raf.

Os caracteres anteriormente referidos para Acacia caven, por sua vez, foram igualmente observados em Acacia ibirocayensis (Marchiori, 1993) e Acacia farnesiana (Marchiori, 2010b), confirmando seu valor taxonômico para a série Gummiferae Benth. e subgênero Acacia Vassal, cujas espécies foram transferidas para o gênero Vachellia Wight \& Arn. (V. caven (Molina) Seigler \& Ebinger; V. ibirocayensis (Marchiori) Deble \& Marchiori e V. farnesiana (L.) Wight \& Arn., respectivamente).

Pertencente ao subgênero Heterophyllum Vassal (e à série Botryocephalae Benth.), Acacia dealbata difere de todas as espécies nativas acima comentadas. A presença de fibras não septadas e com paredes relativamente finas, bem como de raios estreitos (até 5 células), foi também observada em Acacia mearnsii (Costa \& Marchiori, 1980; Marchiori, 1990), Acacia longifolia (Illana \& Marchiori, 1980; Marchiori, 1990), Acacia melanoxylon (Marchiori, 2009), Acacia podalyriaefolia (Marchiori, 2010a) e Acacia decurrens (Marchiori, 2011), todas pertencentes ao subgênero Heterophyllum Vassal, confirmando seu valor diagnóstico para o grupo taxonômico em questão.

\section{REFERÊNCIAS BIBLIOGRÁFICAS}

BURGER, L.M. Estudo anatômico do xilema secundário de sete espécies nativas do gênero Dalbergia, Leguminosae Faboideae. Curitiba: UFPR, 1979. 184 f. Dissertação (Mestrado em Engenharia Florestal - Universidade Federal do Paraná).

BURKART, A. Leguminosas. In: DIMITRI, M.J. Enciclopedia argentina de Agricultura y Jardinería. Buenos Aires: ACME, 1978. v. 1. p. 467-538.
COPANT. Comissão Panamericana de Normas Técnicas. Descrição macroscópica, microscópica e geral da madeira - Esquema I de recomendação. Colômbia, 1973. 19 p. (COPANT 30).

COSTA, A.F. da; MARCHIORI, J.N.C. Estudo anatômico da madeira de Acacia mearnsii De Willd. In: Anais do IV Congresso Florestal Estadual, Nova Prata, Rio Grande do Sul, 1980. p. 237-245.

COZZO, D. Anatomia del leño secundario de las Leguminosas Mimosóideas y Caesalpinóideas argentinas silvestres y cultivadas. Rev. Inst. Nac. Invest. Ci. Nat. Ci. Bot., Buenos Aires, v. 2, n. 2, p. 63-290, 1951.

DUJARDIN, E.P. Eine neue Holz-Zellulosenfaerbung. Mikrokosmos, n. 53, p. 94, 1964.

EWART, A.J. Flora of Victoria. Melbourne: H.J. Green, 1930. 1527 p.

FREUND, H. Handbuch der Mikroskopie in der Technik. Frankfurt: Umsham Verlag, 1970.379 p.

ILLANA, H.A.; MARCHIORI, J.N.C. Estudo anatômico do xilema secundário de Acacia longifolia (Andr.) Willd. In: Anais do IV Congresso Florestal Estadual. Nova Prata, Rio Grande do Sul, 1980. p. 207-215.

MARCHIORI, J.N.C. Estudo anatômico do xilema secundário de algumas espécies dos gêneros Acacia e Mimosa, nativas no Estado do Rio Grande do Sul. Curitiba: UFPR, 1980. $186 \mathrm{f}$. Dissertação (Mestrado em Engenharia Florestal - Universidade Federal do Paraná).

MARCHIORI, J.N.C. Estudo anatômico do xilema secundário e da casca de Acacia recurva Benth. (Leguminosae Mimosoideae). Ciência e Natura, Santa Maria, n. 4, p. 95-105, 1982.

MARCHIORI, J.N.C. Anatomia das madeiras do gênero Acacia, nativas e cultivadas no estado do Rio Grande do Sul. Curitiba: UFPR, 1990. $226 \mathrm{f}$. Tese (Doutorado em Engenharia Florestal - Universidade Federal do Paraná).

MARCHIORI, J.N.C. Anatomia da madeira de Acacia nitidifolia Speg. (Leguminosae Mimosoideae). Ciência Florestal, Santa Maria, v. 1, n. 1, p. 46-63, 1991a.

MARCHIORI, J.N.C. Anatomia da madeira de Acacia plumosa Lowe (Leguminosae Mimosoideae). Ciência e Natura, Santa Maria, v.13, p. 67-77, 1991b. 
MARCHIORI, J.N.C. Anatomia da madeira e casca do espinilho, Acacia caven (Mol.) Mol. Ciência Florestal, Santa Maria, v.2, n. 1, p. 27-47, 1992.

MARCHIORI, J.N.C. Estudo anatômico do xilema secundário de Acacia ibirocayensis Marchiori (Leguminosae Mimosoideae). Ciência e Natura, Santa Maria, n. 15, p. 149-159, 1993.

MARCHIORI, J.N.C. Anatomia da madeira e casca de Acacia tucumanensis Gris. Ciência e Natura, Santa Maria, n. 16, p. 85-104, 1994.

MARCHIORI, J.N.C. Anatomia da madeira e casca de Acacia velutina DC. Ciência e Natura, Santa Maria, n. 17, p. 99-114, 1995.

MARCHIORI, J.N.C. Anatomia da madeira de Acacia bonariensis Gill. ex Hook. et Arn. Ciência Rural, Santa Maria, v. 26, n. 2, p. 209-216, 1996.

MARCHIORI, J.N.C. Anatomia da madeira de Acacia melanoxylon R. Br. Balduinia, Santa Maria, n. 18, p. 26-32, 2009.
MARCHIORI, J.N.C. Anatomia da madeira de Acacia podalyriaefolia A. Cunn. Balduinia, Santa Maria, n. 20, p. 10-15, 2010a.

MARCHIORI, J.N.C. Anatomia da madeira de Vachellia farnesiana (L.) Wight \& Arn Balduinia, Santa Maria, n. 22, p. 9-14, 2010b.

MARCHIORI, J.N.C. Anatomia da madeira de Acacia decurrens Willd. Balduinia, Santa Maria, n. 26, p. 1-7, 2011.

MATTOS, N.F. Espécies conhecidas como "acácia negra", cultivadas no Rio Grande do Sul. Roessléria, Porto Alegre, v. 3, n. 1, p. 67-79, 1980.

MUNSELL COLOR DIVISION. Soil color charts. Baltimore, 1971. s.p.

RECORD, S.J.; HESS, R.W. Timbers of the New World. New Haven: Yale University Press, 1949. 640 p.

ROBBERTSE, P.J.; VENTER, G.; RENSBURG, H.J. van. The wood anatomy of the south african Acacias. IAWA Bulletin, v.1, n. 3, p. 93-103, 1980. 